\title{
Open Prostatectomy for Huge Prostates: Our Experience in a Developing Country
}

\author{
Ibrahim AG, Aliyu S and Ali N*
}

Department of surgery, University of Maiduguri Teaching Hospital and Department of Surgery, College of Medical Sciences University Ff Maiduguri, Nigeria

\begin{abstract}
Background: Benign prostatic enlargement, the most common cause of lower urinary tract obstruction in elderly men is commonly associated with Lower Urinary Tract Symptoms (LUTS). Open prostatectomy is considered the operative treatment of choice. The aim of this study was to review our ten-year experience with open prostatectomy for huge prostates.
\end{abstract}

Patient and methods: We retrospectively reviewed all patients that had open prostatectomy in University of Maiduguri Teaching Hospital from January 2001-December2010, whose prostates weighed $200 \mathrm{~g}$ or more.

Results: Twenty-nine patients aged 60-97 years with a mean age of $76.3 \pm 8.9$ years were analyzed. The age group 80-89 years accounted for highest number of patients. All patients presented with lower urinary tract symptoms of frequency, poor urinary stream, and difficulty in passing urine, urgency/urge-incontinence, nocturia, and hesitancy. Others were incomplete bladder emptying, post-micturition dribbling, and overflow incontinence. Complications of bladder outlet obstruction at presentation were acute urinary retention, renal impairment, stones and haemorrhoids. Intercurrent medical conditions were mainly hypertension and diabetes.

Conclusion: Open prostatectomy is the best option for patients with huge prostates, especially when associated with complications in elderly patients with intercurrent medical conditions.

Keywords: Open prostatectomy; Huge prostates; Presentation; Management

\section{Introduction}

Benign prostatic enlargement is the most common cause of lower urinary tract obstruction in elderly men. This enlargement is commonly associated with Lower Urinary Tract Symptoms (LUTS). The size of the prostate is not directly proportional to the severity of symptoms. Patients present with clinical symptoms as the disease progresses. In developed countries where most patients present early with minimal symptoms and less complications and smaller-size prostates, drug therapy, or minimally invasive techniques like needle ablation, LASER and TURP [1-4], is more appropriate treatment than open prostatectomy. In the developing world, where there is ignorance and lack of access to health facilities, patients present late with complications of bladder outlet obstruction (diverticulae, stones, impaired renal function etc) and large prostates all of which are indications for open prostatectomy [5]. This group of patients are elderly with inter-current medical conditions that are best treated by open surgery [6]. The aim of this study was to review our ten-year experience with open prostatectomy for huge prostates (for the purpose of this study, removed prostate weighing 200 $\mathrm{g}$ or more) in a global era of minimally invasive techniques.

\section{Patients and Methods}

All patients who underwent open prostatectomy for $\mathrm{BPH}$ at the UMTH between January 2001 and December 2010, whose prostate specimen weighed $200 \mathrm{~g}$ or more, were retrospectively reviewed. Details of their bio data, clinical features, investigations, operative treatment, histology reports, postoperative complications and other outcomes of surgery were analyzed using SPSS Version 16. The diagnosis of BPH was made based on clinical assessment which included digital rectal examination DRE, abdomino-pelvic ultrasound scan. Additional tests like PSA and prostatic biopsy were done based on clinical suspicion of malignancy and when confirmed were excluded from the study. Patients gave informed written consent. Clearance was obtained from the hospital Medical and Ethics Committee. All patients had open prostatectomy after resuscitation and continuous catheter drainage were necessary to ensure optimal renal function (based on blood chemistry), and treating any urinary tract infection based on culture sensitivity. Preoperative blood transfusion was given to those that presented with anaemia. All patients had either spinal or general anaesthesia with prophylactic antibiotics (ceftriaxone and metronidazole). Techniques of prostatectomy were either transversical with haemostatic Malament stitch, or retropubic with haemostatic posterolateral suture.

\section{Results}

A total of 32 patients with huge prostates were found in the records. Five were excluded from the study for incomplete data. Patients' ages ranged from $60-97$ years with a mean of $76.3 \pm 8.9$ years. The age group 80-89 years accounted for the highest number of patients 11 (37.93\%) Table 1. All patients presented with lower urinary tract symptoms of frequency in $26(89.66 \%)$, poor urinary stream in $24(82.76 \%)$, difficulty in passing urine, urgency/urge-incontinence in 21 (72.41\%), nucturia in $16(55.17 \%)$, and hesitancy in $13(44.83 \%)$. Others were incomplete bladder emptying in 11 (37.93\%), post-micturition dribbling in

*Corresponding author: Ali Nuhu, Department of Surgery, University of Maiduguri Teaching Hospital, pmb 1414, Maiduguri, Borno State, Nigeria, Tel: +2348065012552; E-mail: nuhualinvwa@yahoo.com

Received February 28, 2013; Accepted July 22, 2013; Published July 27, 2013

Citation: Ibrahim AG, Aliyu S, Ali N (2013) Open Prostatectomy for Huge Prostates: Our Experience in a Developing Country. Trop Med Surg 1: 132. doi:10.4172/23299088.1000132

Copyright: (c) 2013 Ibrahim AG, et al. This is an open-access article distributed under the terms of the Creative Commons Attribution License, which permits unrestricted use, distribution, and reproduction in any medium, provided the original author and source are credited. 


\begin{tabular}{|l|l|}
\hline Age group (years) & Frequency $(\%)$ \\
\hline $60-69$ & $2(6.89)$ \\
\hline $70-79$ & $10(34.48)$ \\
\hline $80-89$ & $11(37.93)$ \\
\hline$\geq 90$ & $6(20.69)$ \\
\hline Total & $29(100)$ \\
\hline
\end{tabular}

Table 1: Age Distribution.

\begin{tabular}{|l|l|}
\hline Complications & Frequency (\%) \\
\hline Acute urinary retention & $17(58.62)$ \\
\hline Renal impairment & $10(34.48)$ \\
\hline Stones & $10(34.48)$ \\
\hline Haemorrhoids & $10(34.48)$ \\
\hline Hernia & $9(31.04)$ \\
\hline Hydronephrosis & $8(27.59)$ \\
\hline Bleeding & $8(27.59)$ \\
\hline UTI & $5(17.24)$ \\
\hline
\end{tabular}

Table 2: Complications at Presentation.

\begin{tabular}{|l|l|}
\hline Complications & Frequency (\%) \\
\hline Transient incontinence & $5(17.24)$ \\
\hline Vesicocutaneos fistula & $4(13.79)$ \\
\hline Clot retention & $3(10.35)$ \\
\hline Errectile dysfuntion & $2(6.89)$ \\
\hline Epididymorchitis & $2(6.89)$ \\
\hline UTI & $2(2.89)$ \\
\hline Wound infection & $2(2.89)$ \\
\hline Others & $4(13.79)$ \\
\hline
\end{tabular}

NB: Others-Renal failure, Irritable bladder, Scrotal haematoma, Cardiac failure, $1(3.45 \%)$ each

Table 3: Postoperative complications.

10 (34.48\%), and overflow incontinence in 3 (10.34\%) duration of symptoms were variable with $4(13.79 \%)$ patients presenting within one year of symptoms, 14 (48.28\%) presenting within 1-4 years while $10(34.48 \%)$ were symptomatic for over 4 years. Table 2 shows the complications of bladder outlet obstruction at presentation with acute urinary retention in 17 (58.62\%), while renal impairment, stones and haemorrhoids each occurring in $10(34.48 \%)$ patients. Intercurrent medical conditions were hypertension in 15 (51.72\%), diabetes in $6(20.69 \%)$, arthritis in 5 (17.24\%), and asthma in 4 (13.79\%), while Parkinsonism and spondylosis occurred in $2(6.89 \%)$ and 1 (3.45\%) respectively. Anaesthesia was spinal in 25 (86.21\%), and general in 4 (13.79\%).The approach was transvesical in 20 (68.97\%), and retropubic in $9(31.30 \%)$. The intra-operative findings were thickened bladder wall in $20(68.97 \%)$, trabeculations and sacculations in $13(44.83 \%)$, bladder stones in $10(34.48 \%)$, and diverticulae in $8(27.59 \%)$. The prostate was globally enlarged in 26 (89.66\%), while isolated median lobe enlargement was found in $3(10.34 \%)$. The weights of removed prostates ranged from $200-426 \mathrm{~g}$, with a mean of $247.77 \pm 56.73 \mathrm{~g}$. PSA (prostate specific antigen) was assayed in 21 patients and the range was 9-25 ng/ml (mean $15.08 \pm 5.05 \mathrm{ng} / \mathrm{ml}$ ). Histology revealed BPH in 28 (96.55\%), while $1(3.45 \%)$ was adenocarcinoma in a background BPH (incidental carcinoma ). Table 3 shows the postoperative complications with transient incontinence in 5 (17.24\%), vesico-cutanous fistula in $4(13.79 \%)$, and clot retention in $3(10.35 \%)$ patients. Other complications included urinary tract infection (UTI), wound infection, erectile dysfunction, and epididymo orchitis each occurring in 2 (6.89\%) patients, while cardiac failure, irritable bladder syndrome, scrotal haematoma, and renal failure occurred in 1 (3.45\%) patient each. Twenty patients had perioperative blood transfusions with 16
(55.17\%) receiving 1 or 2 units of blood while 4 (13.79\%) received more than 2 units. Hospital stay ranged from 1-6 weeks with mean of 15 days. Follow up period ranged from 3 months to 3 years with a mean of 21 months. There was no mortality.

\section{Discussion}

Over the last three decades there has been progressive departure from the traditional open prostatectomy to minimally invasive and robotic techniques for the treatment of $\mathrm{BPH}$. However, these modern techniques require facilities, and a learning curve which are rarely found in developing countries. In such countries open prostatectomy is the main stay. Among this minimally invasive techniques is holmium laser enucleation of the prostate (HoLEP) which has been shown in two randomized trials to have similar results to open prostatectomy with regard to IPPS score $[7,8]$. In these studies patients who underwent HoLEP had much shorter length of catheterization, lower risk of bleeding, lower transfusion rates, shorter recovery rates and shorter hospital stays. These entire parameters sums up to a safer profile for HoLEP but in parts of the world where health budgets are low and where even open prostatectomy can barely be done HoLEP is almost out of the question at this time. Indications still exist even in developed countries for open prostatectomy, which includes large prostates, complications like bladder stones and diverticulae, and intercurrent medical conditions e.g. diabetes and hypertension. Opinions differ among clinicians over what constitutes a Giant Prostate. The Japanese consider $200 \mathrm{~g}$ and above as giant prostates while others consider $500 \mathrm{~g}$ or more $[9,10]$. This study coined the term huge prostate for glands of $200 \mathrm{~g}$ or more. The mean age of 76.3 years is higher than was found in a similar BPH study [11], this is in keeping with late presentation. The clinical features of $\mathrm{BPH}$ are similar in other studies, however complications at presentation were in sharp contrast to what is obtainable in developed countries where recurrent urinary tract infection predominates [11,12]. Huge prostates, diverticulae, stones, and impaired renal function; all features of late presentation are common in developing countries $[13,14]$. Cormorbid medical conditions are associated with peri-operative complications hence the need to optimize such patients for safe surgery [10]. Hypertension and diabetes were the most common intercurrent medical conditions in this group of patients; similar to other study [15]. The mean weight of the removed prostates was $247.77 \mathrm{~g}$, by far more than the recommended EAU guidelines for open prostatectomy (80-100 g). The guidelines

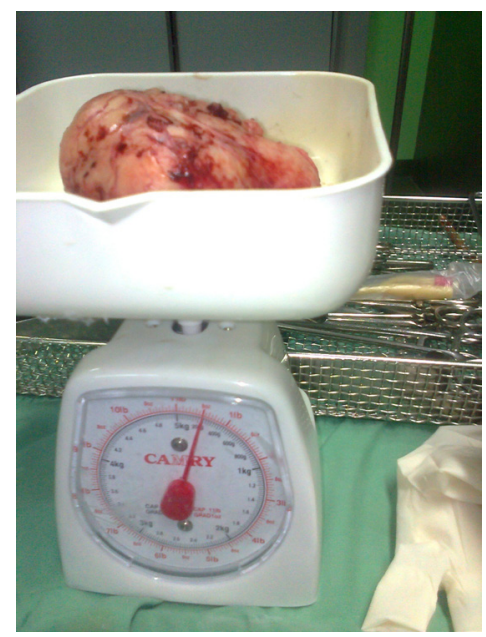

Figure 1: Prototype Huge Prostate Weighing $225 \mathrm{~g}$ 
Citation: Ibrahim AG, Aliyu S, Ali N (2013) Open Prostatectomy for Huge Prostates: Our Experience in a Developing Country. Trop Med Surg 1: 132. doi:10.4172/2329-9088.1000132

Page 3 of 3

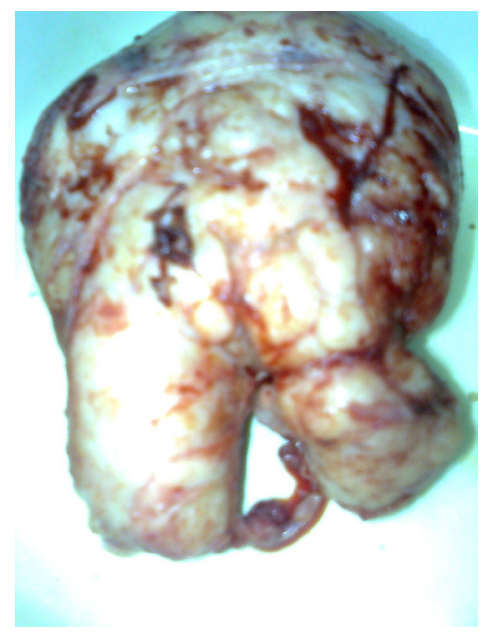

Figure 2: Another Huge Prostate Weighing

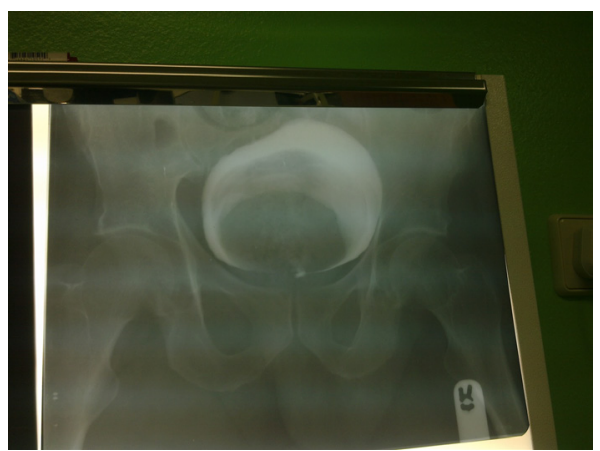

Figure 3: Cystogram Showing Giant Median lobe of The Prostate.

recommended open prostatectomy for prostates more than 80-100 g [15]. Three recent Randomized Controlled Trials (RCT) have shown that Holmium laser enucleation and transurethral photoselective vaporization of the prostate (PVP) have comparable outcomes to open prostatectomies in men with glands between 70 and $100 \mathrm{mls}$ [15]. Absolute PSA values were higher than normal in these huge prostates; though only one incidental carcinoma was reported; (Figures 1-3) this buttressed the unreliability of absolute PSA figures as a diagnostic tool for carcinoma of the prostate as opposed to PSA density [16]. Complications including clot retention, wound infection, and transient incontinence are known to be associated with open prostatectomy [14] and are not any different for huge prostates. Open prostatectomy has longer hospital stay than that done through minimally invasive techniques. There was no mortality in this study in keeping with current trends of decreasing mortality from major urological procedures.

\section{Conclusion}

Open prostatectomy still occupies a prime place in the treatment of $\mathrm{BPH}$, especially in large prostates presenting late with complications in patients with intercurrent medical conditions. It is safe, cost effective with acceptable morbidity.

\section{References}

1. Sieber PR, Rommel FM, Huffnagle HW, Breslin JA, Agusta VE, et al. (1998) The treatment of gross hematuria secondary to prostatic bleeding with finasteride. J Urol 159: 1232-1233.

2. Naslund MJ (1997) "The cost comparison TUNA versus TURP" Journal of Urology 157: 155.

3. Arai Y, Ishitoya S, Okubo K, Suzuki Y (1996) Transurethral interstitial laser coagulation for benign prostatic hyperplasia: treatment outcome and quality of life. Br J Urol 78: 93-98.

4. Hartung R (1995) Transurethral prostatectomy (TURP): Still the gold standard? J Urol (Paris) 101: 18-21.

5. Sood R, Jain V, Chauhan D (2006) Giant prostatic hyperplasia: surgical management of a case. J Postgrad Med 52: 232-233.

6. Kurokawa K, Tamura Y, Ogura H, Kurihara J, Kobayashi M, et al. (1990) Open surgery of elderly patients with benign prostatic hypertrophy. Hinyokika Kiyo 36: 1167-1172.

7. Kuntz RM, Lehrich K (2002) Transurethral holmium laser enucleation versus transvesical open enucleation for prostate adenoma greater than $100 \mathrm{gm} .:$ a randomized prospective trial of 120 patients. J Urol 168: 1465-1469.

8. Naspro R, Suardi N, Salonia A, Scattoni V, Guazzoni G, et al. (2006) Holmium laser enucleation of the prostate versus open prostatectomy for prostates $>70$ g: 24-months follow-up. Eur Urol 50: 563-568.

9. Silva-Gutlerrez A, Perez-Evia CA, Alcocer-Gaxiola B, Martinez-Mendez ME (2010) Giant prostatic hyperplasia: A case report and literature review. Rev Mex Urol 70: 183-6.

10. Concato J, Horwitz RI, Feinstein AR, Elmore JG, Schiff SF (1992) Problems of comorbidity in mortality after prostatectomy. JAMA 267: 1077-1082.

11. Serretta V, Morgia G, Fondacaro L, Curto G, Lo bianco A, et al. (2002) Open prostatectomy for benign prostatic enlargement in southern Europe in the late 1990s: a contemporary series of 1800 interventions. Urology 60: 623-627.

12. Kuntz RM, Lehrich K, Ahyai SA (2008) Holmium laser encleation of the prostate versus open prostatectomy for prostates greater than 100 grams: 5years follow-up of a randomised clinical trials", European Urology 53: 160-8.

13. Hill AG, Njoroge $P$ (2002) Suprapubic transvesical prostatectomy in a rural Kenyan hospital. East Afr Med J 79: 65-67.

14. Kiptoon DK, Magoha GA, Owillah FA (2007) Early postoperative outcomes of patients undergoing prostatectomy for benign prostatic hyperplasia at Kenyatta National Hospital, Nairobi. East Afr Med J 84: S40-S44.

15. Varkarakis I, Kyriakakis Z, Delis A, Protogerou V, Deliveliotis C (2004) Longterm results of open transvesical prostatectomy from a contemporary series of patients. Urology 64: 306-310.

16. Doublet JD, Ciofu C, Fouret $P$, Gattegno B, Thibault $P$ (1995) [The value of PSA density for the diagnosis of prostatic cancer and for the indication of radical prostatectomy]. Prog Urol 5: 211-219, 220. 